\title{
Prediction of recurrent choledocholithiasis by quantitative cholescintigraphy in patients after endoscopic sphincterotomy
}

K H Lai, N J Peng, G H Lo, J S Cheng, R L Huang, C K Lin, J S Huang, $\mathrm{H}$ T Chiang, L P Ger

\begin{abstract}
Background-Endoscopic sphincterotomy (EST) is widely used for the removal of stones from the bile duct, but stones recur in about one fifth of patients.

Aims-To investigate hepatic clearance by quantitative cholescintigraphy (QC) in patients after EST and to discern the relationship between biliary emptying and stone recurrence.

Methods-One hundred and forty nine patients who had EST and clearance of the bile duct for choledocholithiasis were selected. All patients were confirmed to have complete EST by sphincter of Oddi manometry and underwent $\mathrm{QC}$ soon after normalisation of liver function. Regular clinical follow up was performed for each patient.

Results-During a mean 36 month follow up, $22(14.8 \%)$ patients developed recurrent stones in the bile duct. Irrespective of the status of the gall bladder, patients with recurrent stones had a slower hepatic clearance of radioisotope during $Q C$ compared with patients without stone recurrence, but only the differences in cholecystectomised patients had statistical significance. After carrying out multivariate analysis, one parameter of $\mathrm{QC}$, percentage clearance of maximal count at 45 minutes, was found to be the only significant factor for stone recurrence. All recurrent stones in the common bile duct were successfully removed at endoscopy.

Conclusion-Slower hepatic clearance as shown by QC is an important factor responsible for stone recurrence after sphincter ablation.

(Gut 1997; 41: 399-403)
\end{abstract}

Keywords: hepatic clearance; recurrent choledocholithiasis; quantitative cholescintigraphy; endoscopic sphincterotomy

Endoscopic sphincterotomy (EST) is now widely used for the removal of stones from the common bile duct (CBD). In follow up studies after EST, 3-21\% of patients developed recurrent CBD stones and up to $21 \%$ of patients with gall bladder in situ required subsequent cholecystectomy due to cholecystitis, particularly those patients with preexisting cholecystolithiasis or cystic duct obstruction. ${ }^{1-8}$ Recurrent biliary symptoms or new stone formation usu- ally occur within the first one to two years after EST. ${ }^{45}$ No gross abnormality of the bile duct has been noted in patients with recurrent biliary stones after EST, although sphincteric stenosis has been observed in some patients. ${ }^{2}$ However, in a manometric study, Geenen et al observed that sphincteric stenosis is infrequent if EST has been performed with a mean incision length of $1.1 \mathrm{~cm}^{9}$ Besides sphincteric stenosis, biliary stasis and infection are other possible pathogenic factors in primary CBD stone formation. ${ }^{10}{ }^{11}$ Although bacteriocholia is common after sphincter ablation, symptomatic cholangitis does not occur when the clearance function of the biliary tree is excellent. ${ }^{12}$ Impaired biliary emptying is hence believed to be the key factor for recurrent stones. In the present study, we have used quantitative cholescintigraphy to study biliary emptying in patients after EST and complete clearance of CBD stones, and have analysed the possible factors which are likely to influence biliary emptying and stone recurrence.

\section{Materials and Methods}

PATIENTS

Three hundred and forty six patients with choledocholithiasis underwent EST to remove stones from the bile duct between September 1990 and May 1994 in the Veterans General Hospital-Kaohsiung. Patients who agreed to undergo sphincter of Oddi manometry, quantitative cholescintigraphy, and regular follow up visits were included in this study. Patients with suspected retained biliary stones, other systemic diseases, gastric operation, or persistent abnormal liver function for more than 16 weeks were excluded.

FOLLOW UP STUDIES

After EST, all patients who were enrolled in this study underwent liver biochemical tests (including serum total bilirubin, albumin, alanine aminotransferase, aspartate aminotransferase, and alkaline phosphatase) every two weeks until all values returned to normal. Soon after normalisation of liver function, all patients underwent sphincter of Oddi manometry to confirm the complete success of EST, and quantitative cholescintigraphy (QC). The interval between sphincter of Oddi manometry and QC was less than one week. Patients were scheduled for follow up visits and liver function tests every three to six months after sphincter of Oddi manometry and QC. They were
Accepted for publication 2 May 1997 
advised to consult us immediately if any biliary symptoms recurred. Abdominal sonography and endoscopic retrograde cholangiography were carried out whenever symptoms recurred or abnormal liver function was noted. Details of the study were explained to every patient, and written consent was obtained. The protocol was approved by the Research Committee of the Veterans General Hospital-Kaohsiung.

SPHINCTER OF ODDI MANOMETRY

Sphincter of Oddi manometry was performed using a triple lumen polyethylene catheter of $1.7 \mathrm{~mm}$ outer diameter which was introduced through the biopsy channel of a duodenoscope (Olympus JF 1T 20, Tokyo, Japan). The catheter was perfused with sterile distilled water at a rate of $0.25 \mathrm{ml} / \mathrm{min}$ by a pneumohydraulic capillary pump (Arndorfer Medical Specialties, Greendale, Wisconsin, USA). No medication was given during the sphincter of Oddi manometry. We calibrated the pressure of the catheter in the duodenal lumen to zero before cannulation into the bile duct. After deep cannulation, bile was aspirated from one lumen of the catheter to confirm the correct position of the catheter and $2 \mathrm{ml}$ of bile was collected for microscopic examination to ensure the absence of parasitic ova and crystals. Pressure was measured first in the common bile duct, then in the sphincter of Oddi and the duodenum using the station pull through technique. A basal pressure of less than $10 \mathrm{~mm} \mathrm{Hg}$ for the sphincter of Oddi, in addition to a wide opening of the common bile duct, was defined as a complete ablation of sphincteric function.

\section{QUANTITATIVE CHOLESCINTIGRAPHY}

Quantitative cholescintigraphy was performed after intravenous administration of $8 \mathrm{mCi}$ (296 MBq) technetium-99m labelled sodium $\mathrm{N}-[\mathrm{N} 1-(2,6$ diethylphenyl) carbamoylmethyl] iminodiacetate (EHIDA, Amersham International plc, Buckinghamshire, UK) to the patients after overnight fasting. Imaging was carried out using a large field gamma camera with a low energy, all purpose collimator (Siemen Orbiter 75, Chicago, Illinois, USA) connected to a computer (Microdelta, Chicago, Illinois, USA). Data were recorded with the patients in a supine position under the gamma camera. A continuous series of 60 frames of one minute duration each was stored on the computer disk for later analysis. Static views at one, two, four, and six hours were also recorded. A rectangular region of interest was identified and outlined over the right hepatic lobe and a time-activity curve was created. The time to reach maximal count $\left(t_{\max }\right)$, half time for hepatic clearance from $t_{\max }\left(t_{1 / 2}\right)$ and hepatic clearance percentage of the maximal count at 45 minutes and 60 minutes (E45', E60') were recorded for comparison. ${ }^{13}{ }^{14}$ The reference values of the positive limit were $t_{\max }=13$ minutes, $t_{1 / 2}=30$ minutes, $E 45=57 \%$, and E60' $=72 \%{ }^{13}$

\section{STATISTICS}

The results are expressed as mean (SE). Student's $t$ test was used to compare the differ- ences between the two groups. If the variances of the two groups were not equal, the Mann-Whitney $U$ test was used. Survival analysis by the Breslow method was used to compare the differences of the factor time $\left(t_{\max }\right.$, $t_{1 / 2}$ ). The factors affecting stone recurrence and hepatic clearance were analysed by the logistic regression model. The factors (sex, intact gall bladder, juxtapapillary diverticulum) in the regression model were classified as dummy variables $(0,1)$. E $45^{\prime}>57 \%$ was used as the lower normal limit of hepatic clearance for the logistic regression. ${ }^{13} \mathrm{~A} p$ value of less than 0.05 was considered to be significant.

\section{Results}

RECURRENCE OF STONES AFTER EST

One hundred and fifty four patients were enrolled in the study and five patients were excluded from analysis due to basal sphincteric pressure greater than $10 \mathrm{~mm} \mathrm{Hg}$. Of the remaining 149 patients, 57 patients had previously had cholecystectomy and 29 patients underwent a laparoscopic cholecystectomy within one week after EST; the other 63 patients had no further gall bladder surgery after EST due to either old age or absence of cholecystolithiasis. No parasitic ova or crystals were found in the bile in all 149 patients during sphincter of Oddi manometry. Table 1 presents the characteristics of the patients. During the 13-61 month (mean 36 month) follow up period, 11/86 (12.8\%) cholecystectomised patients and $11 / 63(17.5 \%)$ patients with an intact gall bladder developed recurrent CBD stones $(p>0.05)$. Of the 11 patients with recurrent stones and an intact gall bladder, only four had stones in the gall bladder at the time of EST. There was no difference in the time of normalisation of liver function after EST between the patients with or without stone recurrence (4.6 (4.3) weeks versus 5.4 (4.6) weeks, $p>0.05$ ). Eleven patients (five cholecystectomised patients and six with an intact gall bladder) had biliary symptoms at the time of stone recurrence. All recurrent CBD stones were successfully removed at endoscopy. One patient with an intact gall bladder underwent a prophylactic cholecystectomy after endoscopic treatment for recurrent CBD stones; two other patients had elective cholecystectomy due to acute cholecystitis.

\section{HEPATIC CLEARANCE AFTER EST}

Patients with recurrent stones exhibited slower hepatic clearance than patients without recurrent stones; the differences between patients with or without recurrent stones in all param-

TABLE 1 Baseline characteristics of 149 patients

\begin{tabular}{ll}
\hline Sex $(\mathrm{M} / \mathrm{F})$ & $119 / 30$ \\
$\begin{array}{l}\text { Mean (range) age (y) } \\
\text { No. of patients with juxtapapillary }\end{array}$ & $66(31-86)$ \\
$\quad \begin{array}{l}\text { diverticulum (\%) } \\
\text { No. of patients with cholecystectomy } \\
\quad \text { (laparoscopic cholecystectomy) }\end{array}$ & $90(60 \%)$ \\
$\begin{array}{l}\text { No. of patients with an intact gall bladder } \\
\quad \text { (with gallstones) }\end{array}$ & $86(29)$ \\
$\begin{array}{l}\text { Maximal diameter of common bile duct } \\
\quad \text { Cholecystectomised }(\mathrm{cm})\end{array}$ & $63(21)$ \\
$\quad$ Intact gall bladder $(\mathrm{cm})$ & $1.62(0.5)$ \\
\hline
\end{tabular}


eters of QC reached statistical significance in the cholecystectomised patients $(\mathrm{p}<0.05)$. In patients with an intact gall bladder, only the difference in the mean value of E60' between the patients with and without recurrent stones reached statistical significance $(\mathrm{p}=0.04)$ (table 2).

\section{FACTORS AFFECTING RECURRENT STONES AND BILIARY EMPTYING}

The possible factors that may affect stone recurrence were analysed by a logistic regression test. Slower hepatic clearance $\left(\mathrm{E} 45^{\prime}<57 \%\right)$ was the only significant factor for stone recurrence (table 3$)(p=0.0073)$. Using the abnormal E45' as the predictor of recurrent stones, the sensitivity was $86.3 \%(90.9 \%$ in cholecystectomised patients, $81.8 \%$ in patients with an intact gall bladder), and the specificity was $49.6 \% \quad(57.3 \%$ in cholecystectomised patients, $38.4 \%$ in patients with an intact gall bladder). In multiple regression using E45' as a dependent variable, the larger diameter of the common bile duct, and an intact gall bladder were the significant factors responsible for causing delay in hepatic clearance $(\mathrm{p}<0.01, r=$ 0.4 ). Age, sex, presence of a juxtapapillary diverticulum (JPD), previous history of cholangitis, jaundice, and the time for normalisation of liver function after EST did not influence the E45' (table 4). Results were not changed when

TABLE 2 Results of quantitative cholescintigraphy in patients after endoscopic sphincterotomy

\begin{tabular}{|c|c|c|c|c|c|c|}
\hline & \multicolumn{2}{|c|}{ Cholecystectomised } & \multirow[b]{2}{*}{$p$ Value } & \multicolumn{2}{|c|}{ Intact gall bladder } & \multirow[b]{2}{*}{$p$ Value } \\
\hline & No recurrence & Recurrence & & No recurrence & Recurrence & \\
\hline $\mathrm{t}_{\max }(\min )$ & $13.1(1)$ & $17(2)$ & 0.009 & $14.1(1)$ & $17(2)$ & 0.130 \\
\hline $\mathrm{t}_{1 / 2}(\min )$ & 31 (1) & 42 (6) & 0.028 & $37 \quad$ (3) & 56 (19) & 0.180 \\
\hline $\mathrm{E} 45^{\prime}(\%)$ & $54.6(1.8)$ & $35.9(4.5)$ & 0.000 & $46.9(2.4)$ & $37.0(5.2)$ & 0.090 \\
\hline E60' (\%) & $68.5(1.8)$ & $55.9(4.6)$ & 0.012 & $61.8(2.2)$ & $50.8(5.4)$ & 0.047 \\
\hline
\end{tabular}

$t_{\max }$, time to maximal count; $t_{1} / 2$, half time for clearance from $t_{\max } ; E 45^{\prime}, E 60$ ', clearance percentage of maximal count at 45 minutes and 60 minutes.

TABLE 3 Factors affecting the recurrence of common bile duct stones (by logistic regression model)

\begin{tabular}{lrllll}
\hline Variable & Coefficient & \multirow{2}{*}{$S E$} & p Value & Odds ratio & 95\% CI \\
\hline E45' $(<57 \%)$ & 2.0930 & 0.7796 & 0.0073 & 8.109 & $1.76-37.37$ \\
Age & -0.0078 & 0.0268 & 0.2211 & 0.992 & $0.94-1.05$ \\
Sex $(\mathrm{M} v \mathrm{~F})$ & 0.5392 & 0.5748 & 0.3482 & 0.583 & $0.19-1.80$ \\
Size of CBD $(>1 \mathrm{~cm})$ & 0.6035 & 0.7444 & 0.4175 & 1.829 & $0.43-7.87$ \\
Diverticulum & 0.4658 & 0.5173 & 0.3679 & 1.593 & $0.58-4.39$ \\
Intact gall bladder & 0.1348 & 0.4903 & 0.7834 & 1.144 & $0.44-2.99$ \\
History of jaundice & -0.6411 & 0.5138 & 0.2121 & 0.527 & $0.19-1.44$ \\
Cholangitis & -0.2519 & 0.5058 & 0.6184 & 0.777 & $0.29-2.09$ \\
$\quad$ Time for LFT & & & & & \\
$\quad$ normalisation & -0.0022 & 0.0585 & 0.9697 & 0.991 & $0.89-1.12$ \\
\hline
\end{tabular}

LFT, liver function test; CI, confidence interval.

TABLE 4 Factors affecting hepatic clearance (E45') in patients after endoscopic sphincterotomy (multiple regression model)

\begin{tabular}{lcccc}
\hline Variable & Coefficient & \multicolumn{1}{l}{$S E$} & $t$ Value & $p$ Value \\
\hline Age $(\mathrm{M} v \mathrm{~F})$ & -1.33 & 0.14 & -1.72 & 0.086 \\
Sex & -0.02 & -0.02 & -0.265 & 0.791 \\
Diverticulum & 0.02 & 0.03 & 0.30 & 0.767 \\
Size of CBD $(>1 \mathrm{~cm})$ & -12.04 & 2.69 & -4.5 & 0.000 \\
Intact gall bladder & -7.21 & 2.69 & -2.37 & 0.008 \\
History of jaundice & -0.02 & -0.02 & -0.025 & 0.806 \\
Cholangitis & 0.10 & 0.11 & 1.30 & 0.195 \\
Time for LFT normalisation & 0.02 & 0.02 & 0.20 & 0.845 \\
Constant & 71.75 & 4.68 & 15.33 & 0.000 \\
\hline
\end{tabular}

LFT, liver function test.
E60' $(>72 \%)$ was used as a dependent variable instead of E45'.

\section{Discussion}

Quantitative cholescintigraphy is a noninvasive test to evaluate hepatic clearance and biliary emptying. ${ }^{14}{ }^{15} \mathrm{We}$ chose the region of interest over the right liver to avoid higher background activity over the left liver and bile duct. ${ }^{16} 17$ The slopes for disappearance of isotope from the region of the right liver, hilum, and CBD were virtually identical; hepatic clearance in the right liver is therefore comparable to biliary emptying of the CBD in the absence of biliary obstruction and parenchymal liver disease. ${ }^{13}{ }^{14}$ In asymptomatic control patients, more than half of the radioisotope was excreted 45 minutes after administration. ${ }^{13}$ Impaired biliary emptying can be detected by QC even when results of the routine liver function tests are normal. ${ }^{15}$ However, QC is not sensitive enough to differentiate between organic and functional disorders of the biliary tract, especially in patients with a dilated bile duct. ${ }^{18}$

In the present study, organic obstruction of the biliary tract may be excluded by cholangiography soon after EST, normal liver function before QC, and low sphincteric basal pressure on sphincter of Oddi manometry. The abnormal time-activity curve of the QC observed for some patients in this study therefore suggests impaired emptying of the biliary tract. Elta et al have reported frequent occurrence of delayed biliary drainage in asymptomatic patients after cholecystectomy, by observing the 45 minute drainage of contrast media during endoscopic retrograde cholangiography. ${ }^{19}$ The sphincter of Oddi acts as a passive resistor to control the delivery of bile into the duodenum; bile is thought to be freely emptied into the duodenum after sphincteric ablation. ${ }^{15}$ However, in the present study, after complete EST, patients showed wide variation in the parameters of the time-activity curve (for example, $5-81 \%$ in E45') of the QC, indicating heterogeneous of biliary emptying in patients with CBD stones even after sphincter ablation. As patients with recurrent CBD stones exhibited slower biliary emptying than patients without recurrent CBD stones, slower biliary emptying may be assumed to be an important factor for recurrence of primary CBD stones.

The time-activity curve for QC of noncholecystectomised patients has been reported to be unreliable because the gall bladder influences CBD clearance. ${ }^{14}$ In this study, differences in the mean parameters of QC were observed between the non-cholecystectomised patients with and without recurrent CBD stones although only E60' reached statistical significance. Therefore, QC may be considered to be a useful test to predict the recurrence of CBD stones in patients after EST, particularly in cholecystectomised patients. The 45 minute clearance rate (E45') of $\mathrm{QC}$ is the most sensitive parameter of the time-activity curve for the diagnosis of dysfunction of the sphincter of Oddi. ${ }^{13}$ In this study, E45' was the only variable related to the recurrence of $\mathrm{CBD}$ 
stones; sensitivity was $90.9 \%$ in cholecystectomised patients and $81.8 \%$ in patients with an intact gall bladder, but specificity was only $57.3 \%$ in cholecystectomised patients and $38.4 \%$ in patients with an intact gall bladder.

Mean follow up time in this study was 36 months, and recurrent choledocholithiasis may occur five years after EST, so the risk of recurrent choledocholithiasis still exists in aysmptomatic patients with delayed biliary emptying. ${ }^{20}$ Absence of reduction or dilatation in the diameter of the CBD after EST has been found to occur in patients with persistent symptoms or residual stones, ${ }^{21}{ }^{22}$ but dilatation of the CBD was not observed to be a reliable factor for predicting recurrent $\mathrm{CBD}$ stones in this study. An intact gall bladder and CBD diameter were the factors having a significant influence on biliary emptying during QC.

The incidence of JPD increases with age ${ }^{23}$; this may induce bacterial contamination of bile in patients with an incompetent sphincter resulting in primary $\mathrm{CBD}$ stone formation. ${ }^{24} \mathrm{~A}$ JPD was present in $60 \%$ of our patients, probably due to their age (median age 66 years), but it was not a significant factor for recurrent CBD stones or delayed biliary emptying in this study. However the different locations of major papilla around the JPD may cause different hepatic clearance values and affect risk of stone formation. ${ }^{25}$ Further observation of large series should be conducted to stratify the patients with different locations of major papilla around the JPD (especially the 3-5 and 7-9 o'clock positions) and determine their influence on biliary emptying and stone recurrence. ${ }^{25}$

In this study, the rate of recurrence of CBD stones was higher in the non-cholecystectomised patients than in the cholecystectomised patients $(17.5 \%$ versus $12.8 \%)$. The difference, however, was not of statistical significance probably due to an inadequate number of patients. The reasons for the observed higher recurrent rate in the non-cholecystectomised patients are not clearly understood as yet, but in this study slower biliary emptying was noted to be a significant factor for recurrence of CBD stones. Although subsequent cholecystectomy is performed in up to $21 \%$ of Western non-cholecystectomised patients after EST, emergency cholecystectomy for acute cholecystitis is performed only in about $1-6 \%{ }^{1}$ Acute cholecystitis after EST was an uncommon complication (3\%) in our noncholecystectomised patients. Only $33 \%$ of the non-cholecystectomised patients in this study had concomitant stones in the gall bladder. In addition, seven non-cholecystectomised patients did not have preexisting cholecystolithiasis and the other four non-cholecystectomised patients with preexisting cholecystolithiasis still had stones in the gall bladder at the time of recurrent CBD stones. Therefore, the recurrent stones observed in this study are more likely to be primary choledochal stones than secondary stones - that is, stones which migrated from the gall bladder.

All patients in the present study had normal liver function and were manometrically proven to have received complete sphincterotomy before QC, so the slow biliary emptying observed in some patients is not believed to be due to liver impairment or biliary obstruction. The larger diameter of the bile duct, and intact gall bladder are also likely to be factors contributing to slow biliary emptying. The major factor is, however, not clearly understood. Hindering of biliary drainage by duodenal contraction, ${ }^{26}$ reflux of duodenal contents or radioisotopes into the bile duct through an incompetent sphincter, or abnormal hepatic excretion, are other possible factors for delayed biliary emptying on QC, but they could not be identified in this study. Further studies are required to confirm this hypothesis. As patients with a slower biliary emptying on QC have a higher incidence of recurrent CBD stones after EST, close observation is probably necessary for this subgroup of patients.

This study was supported by a grant from the National Science Council (NSC 86-2314-B075B-006) and partly presented at the American Gastroenterological Association Digestive Disease Week, San Diego, May 1995. The authors thank $\mathrm{Mr}$ E-Ming Wang, Miss Nae-Mei Wang, Dr Chia-Fu Chang, Dr Sam- Ming Chen, Dr Tung-Yuan Wu, and Dr Ming-Tse Shen Sam- Ming Chen, Dr Tung-Yuan
for their assistance in this study.

1 Seifert E. Long-term follow-up after endoscopic sphincterotomy (EST). Endoscopy 1988; 20: 232-5.

2 Hill J, Martin DF, Tweedle DEF. Risk of leaving the gallbladder in situ after endoscopic sphincterotomy for bile duct stones. Br f Surg 1991; 78: 554-7.

3 Hawes RH, Cotton PB, Vallon AG. Follow-up 6-11 years after duodenoscopic sphincterotomy for stones in patients with prior cholecystectomy. Gastroenterology 1990; 98: with prio

4 Ikeda S, Tanaka M, Matsumoto S, Yoshimoto H, Itoh $\mathrm{H}$. Endoscopic sphincterotomy: long-term results in 408 patients with complete follow-up. Endoscopy 1988; 20: 13-7.

5 Safrany L, Stenzel M, Endoscopic papillotomy and stone removal. In: Bennett JR, Hunt RH, eds. Therapeutic endoscopy and radiology of the gut. London: Chapman and Hall Medical, 1990: 222-34

6 Hansell DJ, Millar MA, Murray WR, Gray GR, Gillespie G. Endoscopic sphincterotomy for bile duct stones in patients with intact gallbladders. Br F Surg 1989; 76: 856-8.

7 Holbrook RF, Jacoboson FL, Pezzuti RT, Howell DA. Biliary patency imaging after endoscopic retrograde sphincterotomy with gallbladder in situ. Arch Surg 1991; 126: $738-42$.

8 Cotton PB. Endoscopic management of bile duct stones (apples and oranges). Gut 1984; 25: 587-97.

9 Geenen JE, Toouli J, Hogan WJ, Dodds WJ, Stewart ET, Geenen JE, Toouli J, Hogan WJ, Dodds WJ, Stewart ET,
Mavrellis P, et al. Endoscopic sphincterotomy: follow-up evaluation of effects on the sphincter of Oddi. Gastroenterology 1984; 87: 754-8

10 Malet PF, Rosenberg DJ. Cholelithiasis: gallstones pathogenesis, natural history, biliary pain and surgical therapy. In: Haubrich WS, Schaffner F, Berk JE, eds. Bockus gastroenterology. 5th edn. Philadelphia: Saunders, 1995: 2665729 .

11 Cetta F. Do surgical and endoscopic sphincterotomy prevent or facilitate recurrent common bile duct stone formation? Arch Surg 1993; 128: 329-36.

12 Gregg JA, Girolami PD, Carr-locke DL. Effects of sphincteroplasty and endoscopic sphincterotomy on the
bacteriologic characteristics of the common bile duct. $A m \mathcal{F}$ Gastroenterol 1985; 149: 668-71.

13 Peng NJ, Lai KH, Tsay DG, Liu RS, Su KL, Yeh SH. Efficacy of quantitative cholescintigraphy in the diagnosis of cacy of quantitative cholescintigraphy in the diagnosis of
sphincter of Oddi dysfunction. Nucl Med Commun 1994; 15: 899-904.

14 Darweesh RMA, Dodds WJ, Hogan WJ, Geenen JE, Collier D, Shaker P, et al. Efficacy of quantitative hepatobiliary scintigraphy and fatty-meal sonography for evaluating patients with suspected partial common duct obstruction. Gastroenterology 1988; 94: 779-86.

15 Shaffer EA, Hershfield NB, Logan K, Kloiber R. Cholescintigraphic detection of functional obstruction of the sphincter of Oddi-effect of papillotomy. Gastroenterology 1986; 90: 728-33.

16 Meir SB, Chamoritz P. ${ }^{99 m}$ Tc-Disida vs. endoscopic biliary manometry in assessing sphincter of Oddi function. Hepatology 1989; 10: 895-6.

17 Johsi SN, George EA, Pesrilllo RP. Quantitative temporal analysis of ${ }^{99 \mathrm{~m}}$ technetium P-isopropyl iminodiacetic (PIPIDA) as a measure of hepatic function in health and disease. Gastroenterology 1981; 81: 1045-51.

18 Cicala M, Scopinaro F, Corazziari E, Vignoni A, Viscardi A, Habib FI, et al. Quantitative cholescintigraphy in the assessment of choledochoduodenal bile flow. Gastroenterology 1991; 100: 1106-13. 
19 Elta GH, Barnett JL, Ellis JH, Ackermann R, Wahl R. Delayed biliary drainage is common in asymptomatic post-
cholecystectomy volunteer. Gastrointest Endosc 1992; 38: 435-9.

20 Prat F, Malak NA, Pelletier G, Buffet C, Fritsch J, Choury $\mathrm{AD}$, et al. Biliary symptoms and complications more than 8 years after endoscopic sphincterotomy for choledocholithiasis. Gastroenterology 1996; 110: 894-9.

21 Lygidakis NJ. The incidence and significance of common bile duct dilatation in biliary calculous disease. World F Surg 1984; 8: 327-34.

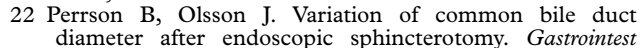
Radiol 1991; 16: 45-8.
23 Osnes M, Løtveit T, Larsen S, Aune S. Duodenal diverticula and their relationship to age, sex, and biliary calculi. Scand f Gastroenterol 1981; 16: 103-7.

24 Løtveit T, Osnes M, Larsen S. Recurrent biliary calculi. Duodenal diverticula as predisposing factor. Ann Surg 1982; 196: 30-2.

25 Huang JS, Lai KH, Lo GH, Peng NJ. Correlation between the location of juxtapapillary diverticula and choledocholithiasis. Endoscopy 1996; 28: S54.

26 Torsoli A, Corazziari E, Habib FI, Cicala M. Pressure relationships within the human bile duct. Normal and abnormal physiology. Scand F Gastroenterol 1990; 25 (suppl 175): 52-7. 